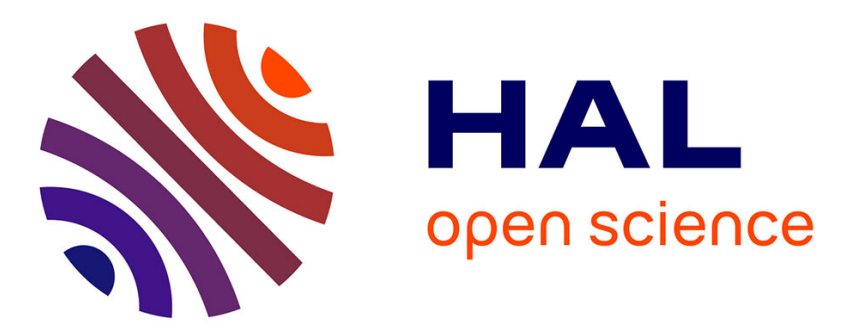

\title{
The social conditions of cultural domination. Field, sub-field and local spaces of wind music in France
}

Vincent Dubois, Jean-Matthieu Méon

\section{To cite this version:}

Vincent Dubois, Jean-Matthieu Méon. The social conditions of cultural domination. Field, sub-field and local spaces of wind music in France. Cultural Sociology, 2013, 7 (2), pp.127 - 144. hal-01361724

\author{
HAL Id: hal-01361724 \\ https://hal.science/hal-01361724
}

Submitted on 17 Feb 2020

HAL is a multi-disciplinary open access archive for the deposit and dissemination of scientific research documents, whether they are published or not. The documents may come from teaching and research institutions in France or abroad, or from public or private research centers.
L'archive ouverte pluridisciplinaire HAL, est destinée au dépôt et à la diffusion de documents scientifiques de niveau recherche, publiés ou non, émanant des établissements d'enseignement et de recherche français ou étrangers, des laboratoires publics ou privés. 


\title{
The social conditions of cultural domination.
}

\section{Field, sub-field and local spaces of wind music in France}

Vincent Dubois, Jean-Matthieu Méon, Cultural Sociology, 7 (2), 2013, p. 127-144.

\begin{abstract}
:
This paper is based on research on wind music in France, where this music is situated at the lowest level in the cultural hierarchy. We examine this music from three points of view: (1) in light of its position in the musical field, (2) as a specific sub-field and (3) at the local level of concrete practices. Then, thanks to the socio-cultural mapping of the orchestras and of their musicians, we establish various combinations of these three levels in the concrete and symbolic organisation of musical activities. This framework allows us to evaluate the various degrees of exposure to cultural domination and the possibilities of escaping it.
\end{abstract}

Keywords: Field, subfield, cultural free zone, cultural domination, wind music, France 


\section{Introduction}

The orchestres d'harmonie in France (more or less similar to the British brass bands ${ }^{1}$ ) are viewed as a symbol of 'lowbrow' folk music, often not even regarded as 'real music'. Contrary to 'authentic' traditional music or to recent popular musical forms (such as rap) wind music has neither benefited from the cultural promotion strategies conducted in cultural public policies since the early 1980s (Dubois, 2011), nor from any kind of intellectual promotion. $^{2}$ Still, despite predictions of the genre's imminent demise, this music remains lively if we think in terms of numbers of bands and musicians (respectively around 2.500 and 100.000 currently registered by the main official organisation). ${ }^{3}$ This proves a good case study to address two main research questions which allow us to elaborate the value of analysing wind music within field analytical terms.

\section{Symbolic domination and cultural hierarchy}

The first question pertains to the debate on symbolic domination and cultural hierarchy. The notion of a structural relationship of homology between the space of cultural forms and the social spaces of positions of producers and consumers, and the subsequent hypothesis positing a parallel between social and cultural domination, as formulated by Bourdieu (1984), has been intensely discussed during the past decades (see for instance Lamont and Fournier, 1992; Bennett et. al., 2009). Here we focus on its implications for the perceptions of 'popular' and 'lowbrow' forms of culture. The hypothesis of the 'choice of the necessary' of the working class unable to master the orientation of their tastes and consumption because of their low level of both economic and cultural capital has been empirically tested (Blasius and Friedrichs, 2008) and theoretically discussed in terms of political implications (Bennett, 2011). Grignon and Passeron (1989) remain faithful to Bourdieu's theory when they argue 
that we have to take into account the dominated position and the symbolic devaluation of these cultures. Otherwise, we pave the way for a naïve and enthusiastic 'cultural populism' that can be sympathetic but neither sociologically relevant nor socially efficient in terms of cultural promotion. But, Grignon and Passeron also nuance this analysis in the light of Richard Hoggart's view of a possible and partial symbolic autonomy of working-class culture (Hoggart, 1957), arguing that cultural domination is not exerted 'always and everywhere' and cannot be the unique viewpoint from which to consider lowbrow forms of culture. Saying that a local amateur folk artist occupies a dominated position does not mean that all his activity can be understood exclusively as domination or that he (or she) cannot escape the feeling of being dominated. We will follow Grignon and Passeron's advice and replace the simplistic, if not normative, question ('is that culture dominated or not?') by a more complex one: what are the social conditions for cultural domination to exert its effects? Or, to put it more specifically, under which conditions and to what extent can 'lowbrow' culture escape cultural domination and achieve a certain degree of symbolic autonomy?

\section{The social organisation of cultural practice}

Understanding the conditions of symbolic domination requires knowledge of the social organisation of cultural practice. This is the second question we have to address. The notion of field as a structured space of struggle between objective positions (Bourdieu, 1996) and that of art world as a network of concrete interactions and cooperation (Becker 1982) are two competing ways of analysing cultural forms. They share the common foundation upon which the sociology of the arts (and by extension part of the sociology of culture) was constructed, stating that art works are collective productions. But in Bourdieu's view, the notions of networks and social worlds focus on the visible forms of interaction and neglect the underlying objective relations that he defines as explanatory factors (Bourdieu and Wacquant, 
1992; Bourdieu, 1996). Conversely, Becker sees the field as a metaphor, not connected enough to 'the real people trying to get things done' (Becker and Pessin, 2006). Consequently, some authors champion networks over fields, as a less abstract and more precise mean to supplement an approach in terms of 'world' (see for instance, Bottero and Crossley, 2011), with more attention to other dimensions of the practice (for instance the technological one, Prior, 2008). Others propose using network analysis as an empirical tool to describe a field, and the distribution of types of capital (Gerhards and Anheier, 1989; de Nooy, 1991) and to better understand how interactions contribute to the definition and structuring of a field (de Nooy, 2003).

Here, following Grignon and Passeron's approach, we reflect upon the various levels of relationships of the production of a cultural form and on the way these levels of relationships are organised or combined. Every cultural practice occupies a specific position in the general cultural field and is also situated in a local system of social relations. As a result we must pay attention to both of these levels and use the relevant concepts to do so; moreover, we must be mindful of the interrelation between these two levels and to their respective effects on the organisation of the cultural form under consideration and on the production of its value. This is the theoretical framework we apply to wind bands.

\section{The social conditions of cultural domination}

We intend to show that the relative weight of the various levels of organisation of a cultural activity, and the way these levels interact with one another are key factors in the variation of the degree of exposure to cultural domination. In other words, we argue that when studying a popular form of culture, we must neither look at it only from the structural/objective point of view of the (legitimate) cultural field (and then conclude that it is nothing but a dominated 
culture) nor see it only from the angle of the concrete relationships of the people involved in this culture (and then conclude that it is an authentic, autonomous culture).

Our first contribution lies in the fact that we consider a cultural form alternatively from these different points of view in order to provide a balanced and comprehensive analysis. ${ }^{4}$ We offer evidence about the internal differences within a cultural form (here, for instance, the differences between wind bands and between their musicians). This is intended to show that even in a dominated universe, there are various positions on a hierarchical scale, from 'the dominating among the dominated' to the most objectively dominated (i.e. those who occupy the lower positions, those further from the legitimate positions). Secondly, more originally perhaps, we show that cultural domination does not necessarily follow this inner hierarchical scale. Indeed, when considering the social conditions for cultural domination, we have to keep in mind that the legitimate cultural hierarchy has to be known, acknowledged and experienced to produce concrete legitimacy (domination) effects in the ordinary practice of the musicians and of the orchestras. As a result, those who are the furthest positioned (objectively and in their concrete experience) from the legitimate cultural positions have more opportunities to ‘forget about domination’ (Grignon and Passeron, 1989), and to weaken its effects, than the ‘cultural claimants' who occupy a higher position but define themselves as would-be legitimate musicians in a ‘cultural goodwill strategy’ (Bourdieu, 1984).

\section{Fieldwork and method}

The research was conducted in 2004-2005 in Alsace, one of the two French regions with the most wind bands and musicians. ${ }^{5}$ It consists of a statistical analysis conducted to objectivise wind music as a space of positions, relationships and practices. Two questionnaires were applied. One was submitted to the musicians, gathering data on their social backgrounds, 
tastes and practices $(n=578)$. The other was sent to the conductors and presidents of musical societies. It consisted of two parts: the first was a sociological survey of these officials $(n=81$ conductors and 125 presidents), the second was about the orchestras themselves and their characteristics $(n=219)$. The resulting data was mapped onto two multiple correspondence analyses, one mapping the social space of the musicians and the other that of the orchestras. We also used traditional multivariate analysis. Additionally, ethnographic fieldwork was undertaken to understand the practices in their immediate environment. We conducted three case studies of bands chosen for their polarised positions in the wind music space. Twentyfive interviews were conducted with musicians, conductors and presidents and direct observations of concerts and rehearsals were carried out. This ethnographic research sheds light on the local dimension of wind band practices, on the habits of the bands and on the characteristics of the musical performances. We conducted twenty interviews with institutional officials from federations and public cultural bodies, in order to understand the institutional structure of wind music. Lastly, we used documentary and bibliographical research to complement the investigation.

In this paper, we will examine the main levels of the social organisation of wind music and the way cultural domination can be exerted and experienced at these various levels. First we address the position of this music in the general cultural and musical field. Secondly, we see its organisation as a specific musical universe in that milieu, and use the concept of sub-field in order to describe it. Then, we focus on the concrete relationships and direct individual interactions among the musicians and between them and their environment. After this threelevel analysis, we elaborate on the relationships between these levels, and show their impact on the intensity of cultural domination. 


\section{Wind bands in the musical field: a dominated position}

Insofar as it relates to the musical field, wind music is in a dominated position, relegated to its fringes. By making this general observation, we do not mean to pass a legitimist judgement on this music, but to acknowledge that it is effectively (and negatively) referred to more legitimate music and excluded from its institutions. This dominated position partly results from an original and 'intrinsic' illegitimacy of this music and its characteristics: a relegation which wind bands and their musicians haven’t been able to shake off.

\section{An illegitimate origin}

Due to a historical separation of strings and winds between the Church and the Army, wind instruments, and thus wind bands, are lower in the instrumental hierarchy than strings. This hierarchy still prevails in contemporary music practice, as exemplified by the fact that wind sections are located at the back in symphonic orchestras. ${ }^{6}$ Yet, the cultural inferiority of wind bands has more specific roots.

Wind bands have their origins in military music but also, more significantly, in the 'orpheonic' movement, which started in the early nineteenth century and reached its peak in the decades before World War One (Gumplowicz, 2011). Orpheon entrepreneurs intended this 'music for the workers' (Fulcher, 1979) to promote safe, moral and civic activities. The polysemy of the word harmonie in French expresses this ambition: the orchestral harmonie (as wind band and musical harmony) being a tool to achieve social harmonie (harmony). Wind music thus clearly appeared to have more social and civic concerns than musical and aesthetic ones, and was outside the musical field strictly speaking. According to one of the Orphéons’ main promotional outlets: ‘At its inception, the Orphéon institution sought to 
reunite the different classes of society through our association. This objective has been reached. The great industrialist, the small merchant, the bourgeois and the worker now get along' ${ }^{7}$ This musical sociodicy, ${ }^{8}$ which defines a specific vision of the social world, of music and of their relationships, remains widespread among wind band musicians and institutional representatives. As a conductor told us: 'The wind band is kind of a blueprint for society as it could be: four generations that have to get along, because when you play the same score, you have to find ways to communicate'.

Musically, orphéons and wind bands were meant to make classical music accessible to a wider (and lower class) audience. This implied a repertoire dominated by simplified transcriptions of great and famous classical works, where original creations were few and neglected by the greater composers (as is still the case nowadays). It also meant a narrower range of instruments, centred on winds - in fact a downsized version of the 'nobler' and 'subtler' symphonic orchestra. In its intents as well as in its forms, wind band music places itself (and is regarded as) in a subordinate position in relation to serious, highbrow music: it can promote it, hint at it but never quite measure up to it.

\section{Symbolic relegation}

This dominated position and lack of recognition still predominates nowadays. ${ }^{9}$ As far as both institutional and commercial outlets are concerned, wind music remains outside of the circuits of cultural consecration. Wind music is indeed absent from prestigious music halls (such as the Parisian Châtelet, Pleyel and Gaveau venues, Garnier and Bastille opera houses), even though they have diversified their programming, opening it to various popular genres (chanson, jazz, world music). Its presence in music academies is somewhat stronger; several local conservatoires still maintain wind bands among their student orchestras, but mainly for 
pedagogical reasons. A wind band may be a step towards group musical practice but only a transitory one, which must be overcome to avoid its supposedly inherent limitations. On the commercial side, a market directed towards wind bands and their musicians does exist (for example, there's a commercial circuit of distribution, often with an international dimension, for wind instruments and scores), but it has no equivalent for their production. Very few companies publish recordings of wind bands. Concerts are usually free, non-commercial events, as they serve as opportunities for the audience to show their support to the band.

Discourses on music reflect and further contribute to this relegation of wind bands. Wind music is almost never featured in mainstream media, except in a stereotypical fashion. Scholarly critique shows little to no interest in wind music: not a single French musicology article or book has been published on this topic, for instance. Accordingly, no scientific or intellectual attempts at rehabilitating this music have been made. Thus, the only discourses that remain are devaluating ones. They range from condescending satire to critical judgements from institutional cultural representatives -the latter being the most harmful, because of their practical consequences (distant and irregular collaborations, funding cuts, etc.). This illegitimacy is also rooted in the social background of the musicians: amateurs, members of rural communities, with predominantly modest social origins (around 2/3 of the musicians) if not low social positions (65\% belong to the lower middle class). ${ }^{10}$ Illegitimate in its origins, from its purpose to its forms and to its social basis, wind music remains illegitimate and unlegitimisable. As we'll see, this illegitimacy is felt by the musicians - but to various extents, depending on their characteristics and positions. 


\section{Wind music as a sub-field: a possible cultural autonomy}

The social reality of wind band music doesn't merely boil down to its dominated position in the musical field. This music also possesses specific structuring principles, defining its own rationales and stakes, which differ from those of the musical field. This relative autonomy from the musical field manifests itself in the objective relationships between wind bands (the correspondences existing between orchestras, based on their socio-musical characteristics) as well as in their effective relationships (objectivised in institutions) and the references, experiences and ethics that emerge and circulate through them. It can therefore be argued that wind bands constitute a sub-field, endowed with a form of cultural autonomy.

\section{The social space of orchestras}

Through multiple correspondence analysis (MCA), the social space of wind bands can be represented on a multi-dimensional space, where two axes synthesize its structuring rationales. Contrary to the musical field (or other specific musical universes such as jazz or rock), style isn't a dividing factor. The heterogeneity of the musicians' musical skills and tastes leads to the (non) choice of an eclectic repertoire that all musicians can play and enjoy. The diverse contexts of the orchestras' performances, from local festivities to official ceremonies, and their heterogeneous audiences, also impose the adjustment of the musical contents to various situations and, as a consequence, add to the eclecticism of the repertoire. Consequently, most bands share a hodgepodge aesthetic without specialising in one style or range of styles. They play 'a little bit of everything', including classical wind music pieces, transcription of classical works, military music, international popular tones or film scores. Discriminations in the social space of wind bands are therefore based on other factors than musical content. 
Instead the relationship to musical practice is the first polarising factor (first axis of the MCA). Two sets of orchestras can be distinguished: on the one hand, bands which are deeply rooted in their local (often rural) space and for whom musical concerns are secondary to sociability; on the other hand, more urban bands, where, conversely, musical orientations are more important than internal sociability. Other differences go with this opposition such as the number of musicians, the musical education of the conductors, or the openness (or local specialisation) of recruitment. The bigger and more urban bands are the most removed from the traditional social practices of wind bands (see below).

The second axis established by the MCA hinges on the ties between the orchestra and a music school. Music schools play a central role in the definition of the orchestras' activities for many reasons. They offer material, human and musical support to the bands, being their breeding-ground and the basis of their stability, but also pass on representations and judgements. Ties to a music school are an indicator of the institutionalisation of the orchestras: the way they are structured, their relations to public institutions (local authorities, mainly) but also, more generally, their integration in the institutionally organised space of this musical practice and its specific events (such as contests).

Combining these two axes, we can distinguish four poles of orchestras. The first one (less institutionalised, more sociability-oriented) includes orchestras whose membership tends to be older and smaller. In the second pole (more institutionalised, more sociability-oriented), the orchestras have many more musicians, including younger ones studying at the music school associated with the orchestra. The biggest orchestras, oriented towards musical content and 
quality, form the third pole, the last one (less institutionalised) being made up of semiprofessional orchestras most often playing ‘folk' or ‘traditional' music.

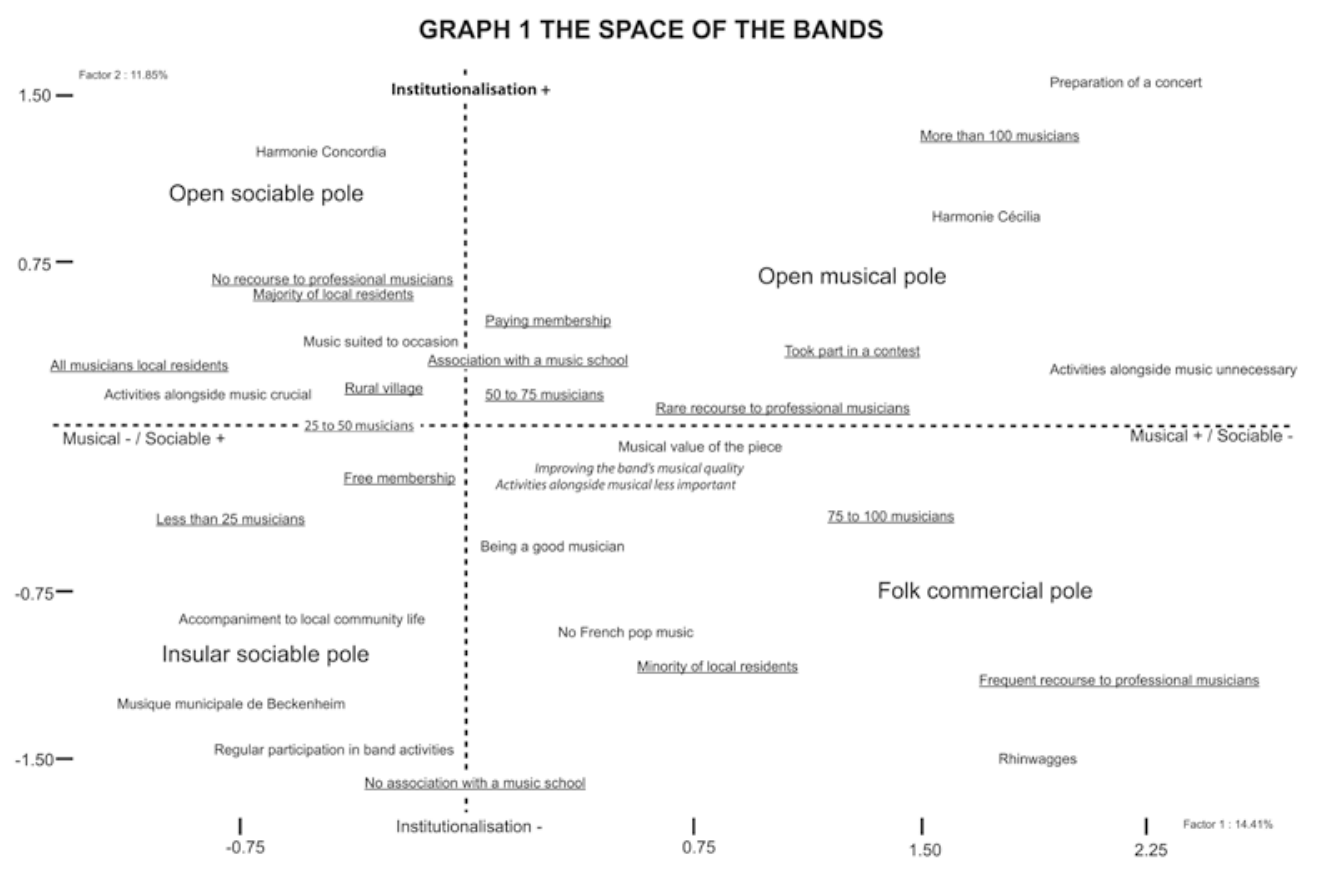

\section{A distinctive, institutionalised universe}

The space of wind music is objectified in specific institutions, with few or no connections to the institutions of the musical field. The basic organisation of this amateur practice is a community one: wind bands are musical associations, gathered in various federations. These give a clear and formal associative framework to the wind bands. They provide them with various types of support (administrative, technical...). They organise events (such as contests) which bring together musicians and orchestras. They contribute to the circulation of information and references, through their magazines and websites, endowing this sub-field with references, rules and stakes of its own. A shared universe is outlined. Thus, they offer an alternative to a full integration into the musical field, a kind of 'universe of consolation' (Poliak, 2006) for those relegated to its margins. 
Common references and shared experiences flesh out the objective and effective structures of the wind music sub-field and further reinforce its autonomy. Specialised composers, a few orchestras, music publishers set the tone, defining models and patterns of practice to be followed by the musicians. These composers and orchestras, which form a common ground for wind band musicians and officials, are quite specific to this universe and seldom known by outsiders.

On prestigious occasions (anniversary, contests), wind band societies invite other bands to perform. Less than a dozen of orchestras play this role of regular distinguished guests at the national level. In accordance with the historical military roots of wind music, they mostly are professional army and police orchestras (Orchestres d'harmonie de la Garde Républicaine, de la Flotte de Brest, Musique des Gardiens de la Paix). Prestige stems from their musical skills, but also from their elite military reputation.

Some composers hold an important and influent position in the wind music universe: their works are played during contests or prestigious concerts and some of them take part in contests or in institutional committees. Those composers have achieved different levels of notoriety and their works cover different musical registers but they share common features among themselves and with wind band musicians in general. They have a real proximity to these orchestras, which they frequented at an early age, which shows in their relationships with wind music institutions. Like many wind musicians who acquired or improved their musical skills during their military service, these composers used to play in military orchestras and often conducted one. They embody the wind music sub-field as much as influencing it. 
Specialised music publishers distribute these references commercially, mainly by selling musical scores and implementing related advertising strategies (demo-CDs which present those scores are widely sent to wind band conductors and officials). This constitutes a constant unifying flow with a direct prescriptive influence on the bands' repertoire.

\section{Specific rules and values}

There is a strong tradition of contests for wind bands, inherited from the orpheonic movement. They are organised by federations at local, regional, national or even international levels. Wind bands perform mandatory programmes in front of juries that award honorific titles. Only a few of the orchestras take part in such events, ${ }^{11}$ but all musicians know them. The importance of these competitions for the cultural autonomy of wind music is twofold. First, for the musicians, they are a physical manifestation of the existence of the socio-cultural universe to which they belong. In the same place and at the same time, numerous musicians, bands, commercial and institutional actors gather for a shared event. Second, they offer a specific form of certification for the orchestras. Delivered by the institutions of wind music, this consecration doesn't entail judgements from the legitimate musical field. Furthermore, in such contests, wind bands do not so much compete with each other as seek institutional validation of their skills from juries of wind band specialists. For institutional officials, contests are meant to promote collective band efforts and self-improvement rather than competition, in line with the wind bands' ethics.

As contests show, alternative types of legitimisation can prevail in the wind music sub-field. They are conveyed in institutional discourses, publications or reports and by the musicians themselves but are also objectified in specific rites and practices. A specific ethic partly 
originates from the orpheonic movement but syncretically builds on secular, religious and military values and a community spirit. It extols the virtues of social and generational mixing and asserts the educational benefits of wind band music, teaching civic values such as togetherness, mutual respect, discipline or mutual help and attachment to the local community.

One of the main aspects of this ethic is its devaluing of musical skills. As our questionnaire shows, musicians and wind band officials alike see musical skills as second to the other qualities of a musician, such as participation in the group's activities or his good companionship. In the eyes of its members, the wind music sub-field finds legitimacy in its ability to integrate everyone, according to a worldview that gives 'a place to everyone':

'Being a good musician is not necessarily a factor. We don't select people on the basis of their level. [...] We don't go ‘you, you're rubbish, we're not taking you'. Whoever wants to come comes, and then we try to make do with the people we've got' (Claude, trumpet player, band president, France Télécom employee, 41 years old).

The medals given to musicians and conductors by the federations are one of the clearest expressions of this ethic. They are completely different from those awarded by music academies, which acknowledge musical excellence, in that they are handed out as a reward of long-term commitment to the band. For example, the Alsatian federation awards medals after 10 (bronze), 15 (silver) or 25 (gold) years of participation. They recompense loyalty and dedication to the group. The recognition goes to the good fellow or citizen rather than to the good musician. In that sense, those medals can only have limited value outside the specific market of symbolic goods that constitutes the wind music sub-field and/or the social local space. For outsiders, such medals appear as a residual folk tradition. 
This ethic also manifests itself in the relationship to professionalism. In general terms, professionalism, when considered in relation to amateur practice, embodies excellence against weakness or mediocrity. In wind music, when the professional model is mentioned at all, it is seen negatively, as a counter-example: the disinterested involvement of the amateur is contrasted with the self-interested (i.e. paid) participation of the professional. ${ }^{12}$ Interviews conducted with musicians show how the professionals who play with amateur bands are seen as a possible threat to their internal balance and overall atmosphere:

'As soon as there's dough involved, the atmosphere gets worse. There are people who come from elsewhere. There are even bands where they have guys playing instead of someone who was there at rehearsal... It rarely happens, but it's really when the director... It’s not nice, you see?' (Alice, horn player, student at the regional music academy, 20 years old).

\section{No domination in a cultural free zone? Local social spaces and direct interactions}

The tensions between the relegated position of wind bands in the musical field and their relative cultural autonomy are partly resolved by the closed and local environment in which this practice takes place. Our fieldwork and statistical analyses show that it is mainly restricted to local interactions and relationships. This allows most of the bands and their musicians to operate in a cultural 'free zone' (Bourdieu, 1991), a social space protected from outside judgements and, more specifically, from legitimate cultural verdicts.

The activities of wind bands generally rely on direct relationships between musical societies and, even more, between musicians. Formal relations between societies are few and consist in mutual invitations to play in their respective towns or occasional common events. They meet practical needs, such as ensuring funding or access to human resources. But most of these 
contacts between wind bands depend on informal and interpersonal relationships: the officials who meet in various musical events or more passionate and committed musicians who play in several orchestras, often to 'lend a hand'. Local specialised networks in which information, references (in objectified forms such as musical scores) or reputations circulate result from inter-acquaintanceship and mutual help, and are removed from external judgements.

At a local level, wind music forms a non-specific universe. It takes place in direct continuity with community life and ordinary relationships. Recruitment of musicians is characterised by local as well as social proximity. Orchestras recruit their members in the same local social groups, if not in the same families. More than half of the musicians (53\%) live in the town of their orchestra, $75 \%$ live less than $10 \mathrm{~km}$ from this town. $80 \%$ of musicians have a relative who plays or has played in their own band.

Family, friendship, neighbourhood ties unite the musicians, who share a common sense of belonging to a place and sometimes specific regional features (such as the use of the Alsatian dialect). All of this contributes to creating a protective community (Hoggart, 1957).

In most cases, neither the musicians' trajectories nor the ordinary activities of the musical society challenge the comfort of this enclosed universe. Few musicians have taken musical lessons outside of their musical society (15\% went to a musical academy). As we have said, loyalty is strong among musicians, whose musical career often takes place in one single orchestra. In the same way, the bands' performances also preserve this homogeneous social frame. They seldom perform further than a dozen kilometres from their hometown. The exposure to external (and less favourable) reactions is necessarily limited by such a smallscale geography, one of the main effects of which is to ensure that the audiences are mostly 
made up of relatives and acquaintances. A judgement based on outside cultural referents (for example, highbrow musical judgements) would be, metaphorically and strictly speaking, out of place. Besides audiences, wind bands have contacts with various institutions, ranging from other local associations (sports clubs, etc.) to public institutions (local, regional or national). The nature and diversity of these institutions vary according to the wind bands' characteristics, but mostly these contacts are either rare or restricted to institutions which are part of the local social space (city council).

\section{Social structures of musical practice and social conditions of cultural domination}

We have seen that the strength of possible cultural domination varies depending on the structural level considered. Firstly, it is at its maximum if we think in terms of the position of wind music in the musical field. Secondly, there are some possibilities for organisational and symbolic autonomy that weakens cultural domination at the intermediate level of the specific sub-field of wind music, where specific values, rules and consecration modes can provide an alternative to the dominant legitimate ones. Thirdly, the recruitment in close circles and the rarity of connections and direct contacts with an exterior audience, with the most legitimate pole of the musical field or with specialised cultural institutions can protect musicians from the legitimate verdicts and allow them to 'forget about domination'.

If all three levels are always simultaneously influential in wind music, their effective impact both on the concrete organisation and on the symbolic representations of this musical practice for the musicians varies according to the characteristics of the orchestras and musicians and in relation to social context. 


\section{Objective positions and effective domination}

The MCA mapping the positions of the orchestras is useful to establish the principle of the variations and oppositions in this socio-musical space (see above). It is also useful to identify the space of references and practical horizons that play the most significant role according to the poles we identified. In the upper right quadrant are the orchestras closest to cultural institutions, regional music schools and professional musicians, i.e. closest to the legitimate musical field (about 20\% of all bands). They are the most legitimate in the wind music subfield and the ones on which its specific rules play the most important role. ${ }^{13}$ They also are the most exposed to the external devaluating judgements because of their more frequent contacts with legitimist agents and institutions of the musical field. Conversely, the orchestras in the lower left quadrant (15 to $20 \%$ of all bands) can be viewed as the dominated among the dominated: not only agents of the musical field but also wind bands on other poles look down on them and so do most wind bands officials. That said, the local organisation of these bands as cultural free zones provides them with a greater degree of protection against symbolic devaluation. In other words there is no mechanical correspondence between the objective dominated position and the concrete impact of domination in terms of orientation of the activity and in terms of experience by the musicians: the orchestras located at the most dominated positions experience less cultural domination than those closer to the legitimate agents and institutions. The third pole, a major one (55-60\% of the orchestras), is intermediate. Here the bands try to maintain a balance between expectations in terms of musical quality (i.e. legitimate criteria) and the simple and sociable traditional atmosphere. It is also at this pole that tensions are the most visible between the groups within the bands, oriented towards one or the other of those two opposed directions. 
The same kind of argument can be presented if we move from the orchestras to the musicians (see below). Musicians who have not been trained in good music schools, who play with their friends and relatives with no better musical skills than theirs and who give a concert only once a year in their home village are the most dominated from the point of view of their objective position. But they also are the least aware of cultural hierarchies and the least exposed to legitimate judgements. Within the relationships that directly matter to them (family, acquaintances, neighbours and colleagues) their practice is regarded as valuable: hence they meet the conditions of forgetting about domination. Conversely, the better-trained and most committed musicians, eager to be recognised as 'real musicians' (a common phrase among them) know about cultural hierarchy and have interiorised the symbolic domination of the music they play. However, if their position is less dominated, they experience cultural domination more intensely and adjust their practices accordingly, showing cultural good-will in trying to fit with the legitimate criteria according to which they are devaluated.

Of course these variations are determined by objective factors such as location (rural orchestras and musicians are usually closer to a free zone organisation when urban ones have more connections with professionals and institutions), social background and status (as Bourdieu has shown in Distinction (1984) cultural good-will is a common attitude among the middle-class), gender and generation (the younger musicians, more often female than in the older generation, pay more attention to legitimate musical aspects when the older ones are more focused on traditional sociability). 


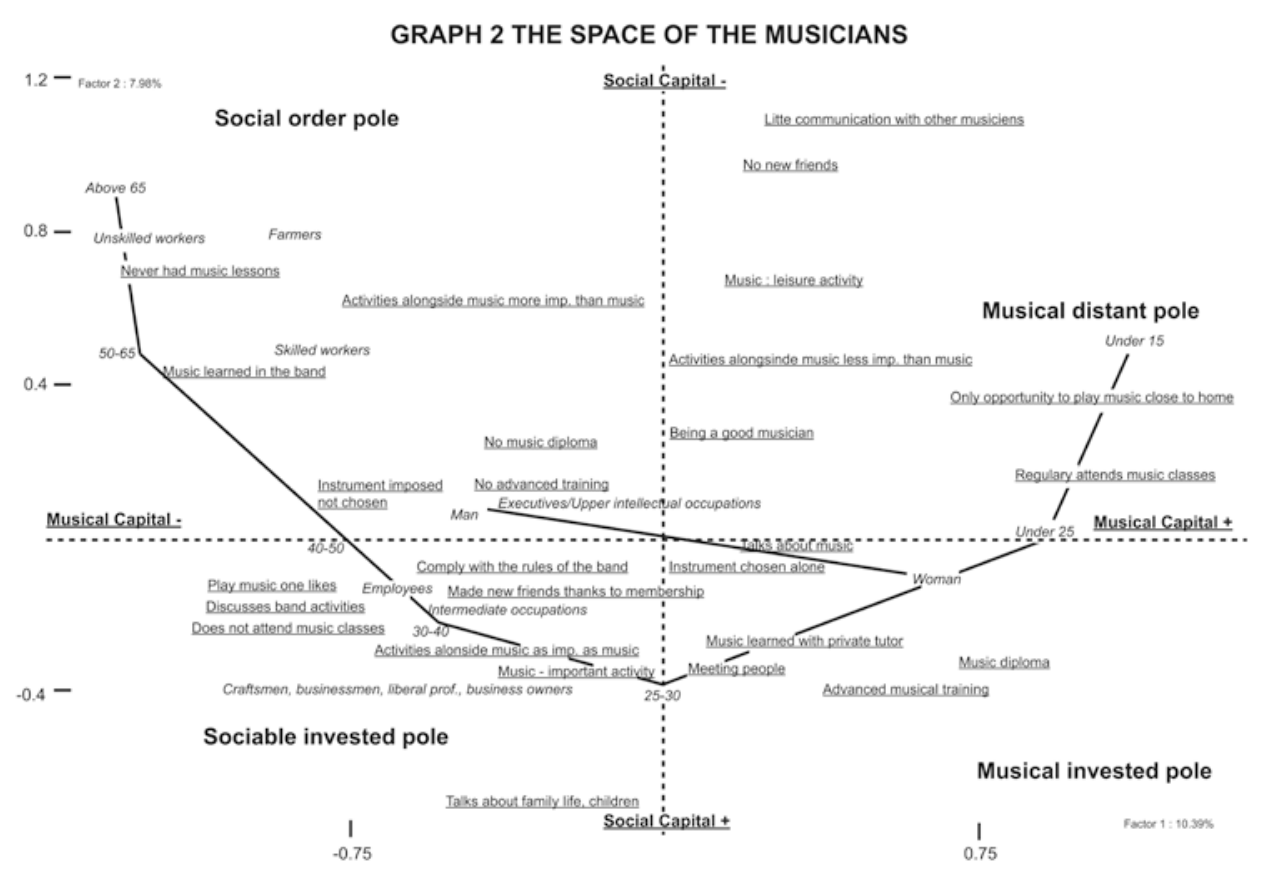

\section{Ongoing changes}

The effects of cultural domination vary according to the position occupied in the wind band space. They also vary diachronically affecting the dynamics of social changes.

First, general social changes have weakened the traditional link between wind bands and their local community. The decline of traditional working-class sociability due to unemployment and the decrease of collective solidarities in the workplace challenge the conditions of collective musical practices in these social milieus as well as the possible symbolic autonomy of this cultural form. The transformation of rural spaces (see Champagne 2002) with the 'rurbanisation' process and the arrival of new social categories (urban middle-classes) in villages introduces (or at least reinforces) external cultural values and references according to which wind bands are devaluated. Access to higher education for rural and/or lower middle class youth can also play a negative role for the orchestras. It often implies a geographic mobility that prevents the young musicians from continuing to attend rehearsal and concerts 
in their home village or small town and also has a negative impact at a symbolic level when these young musicians confronted with urban cultured students first experience the devalued status of the music they play.

Second, we must take into account the recent transformations in the social recruitment of wind band musicians. The joint processes of feminisation, elevation of the social origins and elevation of the musical skills have a direct impact on the expectations and cultural strategies of the musicians. The new type of musicians is less attached to traditional values of sociability and togetherness related to the 'free zone' of socio-musical community. Their involvement in wind bands is mainly musical, seen in terms of quality and improvement. As a consequence, they also bring legitimate references to orchestras where they were previously not relevant. Conflicts arise between generational groups who value different forms of capital (here mainly the traditional form of social capital of older generations versus cultural capital valued by younger generations).

Lastly, we must consider the changes brought about by cultural strategies and policies. Here we can think of the increasing role of the cultural intermediaries of wind band music. (Semi)professional conductors and institutional managers invest wind bands as a niche, which does not lead to prestigious positions but allows for a degree of freedom and multi-tasking that is far more difficult to obtain in other parts of the music sector. Their personal aspirations orient them towards music institutions and legitimate music in a perspective of professional recognition. This process contributes to bringing to wind music the legitimate verdicts and rules from which it was relatively protected. Here we can speak of a two-step flow of symbolic domination, ${ }^{14}$ exerted indirectly on the musicians by the intermediaries who set the (legitimate) tone for wind music and its evolution. 
These cultural intermediaries form the social basis for 'cultural renovation' programmes launched by public cultural institutions and by the federative institutions of wind bands. These modernising strategies aim, at least, at redefining the practice by strengthening its musical dimensions - even if it means somehow to weaken its traditional social components. National and local federative institutions and local public institutions promote a professionalisation of the supervising staff of wind bands, through initiatives such as specific musical education or official certifications for conductors. This is a source of conflict among musicians and orchestras, depending on their respective positions in the wind band space. Another central aspect of these strategies lies in the actual musical content. The wind bands' repertoire is renewed in various ways. This reflects the legitimist negative judgements of institutions and cultural intermediaries towards the common repertoire. Ambiguously, these efforts are more effective with orchestras which are already the most prone to adhering to this renewal and conforming to legitimate cultural principles. Nevertheless, they illustrate a tendency not to promote wind band music per se but to make it fit with the legitimate criteria of the musical field.

MCA analysis is meant to present the structure of a field at a specific moment. Yet, this structure, as seen through the MCA, reflects the (temporary) balances produced by the changes the field has experienced and bears traces of previous evolutions. In addition to that, the oppositions in the musicians' space are partly grounded in generational differences. The graph shows how older musicians (with lesser musical skills and greater distance to the legitimate musical field) are making way for younger ones, with higher skills but greater submission to legitimate criteria (from top left part of the graph to bottom left to right half). In a similar way, in the orchestras' space, we can see the most traditional bands (bottom left) 
being progressively replaced by 'modernised' and more legitimacy-conform ones (top left, top right) or folk and semi-commercial bands (bottom right). Thus, the graphic presentation of the field can also be read dynamically as an outline of ongoing changes.

\section{Conclusion}

Our conclusion is twofold. First, we have tried to show that it is useful to conduct an analysis at different levels, using various concepts adjusted to these levels. As a result we combined a structural approach in terms of objective positions and relationships with the analysis of concrete experiences and direct interactions, this second approach brings nuances to the first one, especially concerning the domination effects field analysis entails. It does not mean that there are no logical hierarchies between these different approaches and concepts. In our opinion field analysis and the objectification of social spaces remain the most powerful, as they allow the results of an interpretive or interactionist approach to be placed in a more general perspective. ${ }^{15}$

Secondly, we think it is necessary to go beyond the debate on cultural domination and hierarchy in simplistic terms of 'domination always and everywhere' or the absence of consideration for the social structures of cultural tastes and practices (as in some of the 'pragmatist' approaches for instance: Prior, 2011). To do so, we suggest paying attention to the social conditions of cultural domination (and conversely to the social conditions of the possible absence of cultural domination). This agenda calls for implementing a multi-level analysis, as we have done here, since the results obtained at one level complement and nuance the others. Rather than merely juxtaposing these different levels we intended to show the way 
they are embedded and organised. The notion of sub-field is pivotal here: when its existence is empirically established (as we demonstrated for wind bands), it allows us to consider objective hierarchical relationships while underlining autonomous practices and representations.

We used this framework to propose a balanced view of a cultural form often seen in a stereotypical manner. Field theory doesn't necessarily lead to a miserabilist view of illegitimate (dominated) practices. It provides the framework to analyse autonomous practices and protection against domination through attention to other levels of organisation. If our approach is above all a 'spatial' one (following the basic principles of field analysis) it is also a dynamic one. We have shown that if wind bands could enjoy a relative symbolic autonomy despite their objective dominated position, the conditions for this symbolic autonomy are less and less met. In that sense our conclusion is not that cultural hierarchies are softened, challenged or no longer exist because of a new cultural mix, but that due to some of the transformations we have underlined these hierarchies apply, more than they used to, to such a 'lowbrow' traditional form of working-class culture. We hope that this framework can be usefully applied to other cultural forms and in other contexts.

\section{References}

Anheier HK, Gerhards JP and Romo FP (1995) Forms of Capital and Social Structure in Cultural Fields: Examining Bourdieu's Social Topography. American Journal of Sociology 100(4): pp. 859-903.

Ardery JS (1997) 'Loser wins. Outsider art and the salvaging of disinterestedness. Poetics 24(5): pp. 329-346.

Becker HS (1982) Art Worlds. Berkeley: University of California Press. 
Becker HS and Pessin A (2006) A Dialogue on the Ideas of 'World' and 'Field'. Sociological Forum, 21(2): pp. 275-286.

Bennett T (2011) Culture, choice, necessity: A political critique of Bourdieu's aesthetic. Poetics 39(6): pp. 530-546

Bennett T, Savage, M Silva E, Warde A, Gayo-Cal M and Wright D (2009) Culture, Class, Distinction. London: Routledge.

Blasius J and Friedrichs J (2008) Lifestyles in distressed neighbourhoods: a test of Bourdieu's taste of necessity hypothesis. Poetics 36(1): pp. 24-44.

Bottero W and Crossley N (2011) Worlds, Fields and Networks: Becker, Bourdieu and the Structures of Social Relations. Cultural Sociology 5(1): pp. 99-119.

Bourdieu P (1984) Distinction: a Social Critique of the Judgement of Taste. London: Routledge.

Bourdieu P (1991) Language and Symbolic Power. Cambridge: Harvard University Press.

Bourdieu P (1996) The Rules of Art. Cambridge: Polity.

Bourdieu P and Wacquant L (1992) An Invitation to Reflexive Sociology. Cambridge: Polity.

Champagne P (2002) L'Héritage Refusé. La Crise de la Reproduction Sociale de la Paysannerie Française, 1950-2000. Paris: Seuil.

De Nooy W (1991) Social networks and classification in literature. Poetics 20(6): pp. 507537.

De Nooy W (2003) Fields and networks: correspondence analysis and social network analysis in the framework of field theory' Poetics 31(5-6): pp. 305-327.

Dubois V, Méon J-M, and Pierru E (2013) The sociology of wind bands. Amateur music between domination and autonomy. Aldershot: Ashgate.

Dubois V (2011) Lowbrow culture and French cultural policy: the socio-political logics of a changing and paradoxical relationship, International Journal of Cultural Policy 17(4): pp. 394-404.

Finnegan R (1989) The Hidden Musicians: Music-Making In An English Town. Cambridge: Cambridge University Press.

Fulcher J (1979) The Orpheon Societies : 'Music for the Workers' in Second-Empire France. International Review of the Aesthetics and Sociology of Music 10(1): pp. 47-56.

Gerhards J and Anheier HK (1989) The Literary Field: An Empirical Investigation of Bourdieu's Sociology of Art. International Sociology 4(2): 131-146.

Grignon C and Passeron, J.-C. (1989) Le Savant et le Populaire. Paris: Gallimard-EHESS.

Gumplowicz P (1985) Le dossier 'orphéon' : musique et sociabilités. In Révoltes logiques, Esthétiques du peuple. Paris : La Découverte-Presses Universitaires de Vincennes. pp. 55-76. 
Gumplowicz P (2011) Les Travaux d'Orphée. Deux Siècles de Pratique Musicale en France (1820-2000): Harmonies, Chorales, Fanfares. Paris: Aubier.

Hoggart R (1957) The Uses of Literacy. London: Chatto and Windus.

Lamont M and Fournier M (eds) (1992) Cultivating Differences. Symbolic Boundaries and the Making of Inequality. Chicago: University of Chicago Press.

Poliak C (2006) Aux Frontières du Champ Littéraire. Sociologie des Écrivains Amateurs. Paris: Economica.

Prior N (2011) Critique and Renewal in the Sociology of Music: Bourdieu and Beyond. Cultural Sociology 5(1): pp. 121-138.

Shusterman R (1999) Moving Truth : Affect and Authenticity in Country Musicals. Journal of Aesthetics and Art Criticism 57(2): pp. 221-233.

${ }^{1}$ See Finnegan’s study of 1980s bands in Milton Keynes (Finnegan, 1989: 47-57). French and British histories, ethics and current evolutions of such bands have much in common, even though British ensembles enjoy much more visibility and prestige, thanks to closer relations with legitimate musical institutions and to television programmes and movies, such as Mark Hermann’s 1997 Brassed Off .

${ }^{2}$ For an example of a similar intellectual neglect in the context of country music, see Shusterman, 1999.

${ }^{3}$ Source: Confédération musicale de France (CMF), Paris.

${ }^{4}$ Finnegan (1989) describes the local world (in Becker's sense) of brass bands. This allows her to underline the autonomy and specificities of the brass bands, which unify their musicians and distinguish them from other musical worlds in their town. Even though we share many results with Finnegan's study, our approaches differ. The world approach precludes the analysis from showing differences between the different bands and musicians and the nature of their objective relationships (be it antagonistic, cooperative or hierarchical). It also offers few elements regarding the relationships with the other worlds and the possible judgements they entail. Our approach includes the objectivation of positions, relationships 
and hierarchies within the musical field and the wind music sub-field, in addition to the study of concrete local relationships.

${ }^{5}$ See Dubois, Méon and Pierru (2013) for further methodological and empirical details.

${ }^{6}$ B. Lehmann states that acoustic constraints do not justify such a position, as other dispositions have been used for orchestras (Lehmann, 2002).

${ }^{7}$ L’Orphéon, 5 July 1986, cited in Gumplowicz 1985: 67, our translation.

${ }^{8}$ Sociodicy is a neologism by Bourdieu indicating a coherent system of representations of the society and of interpretations of social phenomenon justifying the world as it is.

${ }^{9}$ The relegation of wind band music may not be as strong in other contexts as it is in France. The cultural and intellectual status of this music varies from one country to another, due to historical, institutional and/or social factors. See preface in Dubois, Méon and Pierru (2013) for comparative propositions.

10 This is an important question, not elaborated on it in this paper. See Dubois, Méon and Pierru (2013) for further discussion.

${ }^{11}$ In our research, two thirds of the responding orchestras hadn't taken part in a contest for the last five years. According to the French federation, 10 to 15\% of all orchestras take part in national contests.

12 On the opposition between the 'disinterestedness' of folk and outsider artists and the ‘careerism’ of academically trained artists, see Ardery (1997).

${ }^{13}$ They are the ones who participate in the contests, for instance.

14 To paraphrase Lazarsfeld's famous formula of a two-step flow of communication in media influence.

${ }^{15}$ In that sense we think that contrary to what Bottero and Crossley (2011) propose it is not possible to deduct the structure of a field from concrete interactions in a network. Conversely 
we think that network analysis can be a useful complement when the space of objective positions and relationships has been mapped first. 